\title{
ADMINISTRATION OF LIBRARIES AT DISTANT SITES AND REMOTE TELESCOPE LOCATIONS
}

\author{
Ellen Bouton \\ National Radio Astronomy Obs. \\ Charlottesville, VA USA
}

\author{
Maria Eugenia Gómez \\ European Southern Observatory \\ La Silla, Chile
}

Many librarians are responsible for libraries at outstations and/or remote telescope sites. Such sites may range in size from facilities with as many personnel as the central headquarters to remote observing stations where only a few people are present at any one time. Sites may be only a few kilometers away, or they may be half way around the world. In an informal evening discussion, concerned librarians discussed issues and problems created by such far-flung library systems.

Budgetary constraints are a primary problem in managing site libraries at most institutions. Staff and visiting scientists want duplicates at the sites of the books and journals they use regularly in their work, but with current prices it is often difficult to provide even the major astronomy journals for site as well as central libraries. Even when researchers are encouraged to do preparatory research before going to observe, some library materials may still be necessary. In the case of larger sites where people work on a permanent basis, larger collections will, of course, be needed. It is especially important at such sites to provide easy access for materials directly involved in preparation of observations, e.g. photographic sky atlases, reference catalogs of astronomical objects, etc. We discussed at length the problems of selection and acquisition of materials for remote libraries, including questions of purchasing and technical processing, binding, inventory, and bibliographic control.

Staffing is another problem, with the librarian at the central headquarters often being responsible for the remote libraries. In many cases, all library care must come from the librarian on occasional visits to the site. Sometimes there is a staff person at the site who can give some minimal care to library, and in a few cases there is actually a full- or part-time professional librarian to staff the site. We agreed that when librarians are fully responsible for libraries in more than one location, they often lack time for anything more than minimal service to the distant locations. Discussion of library staffing also included such issues as lending policies and collection security, library users' manuals and instruction sheets, and the handling of reference questions or requests for specific materials from staff or visitors.

We discussed problems of transporting materials between an institution's libraries, both on a routine basis and in cases where something is needed more quickly. Solutions to transport problems ranged from FAX through air freight and regular internal shuttle runs to the slower solution of surface mail. 
We stressed the importance of new technologies such as e-mail, not only in fostering communication between librarians at different institutions, but as a way of maintaining an ongoing dialog between the main library and the librarian or other staff person responsible for the site library.

Librarians have developed a variety of solutions to the problems of administration and care of site libraries. These solutions depend on the distance between libraries, the specific requirements of individual institutions, and the budgetary allocation for the library system. We have differing arrangements to care for our multiple libraries, and we continue to search for better ways to serve our diverse and distant library users. 